
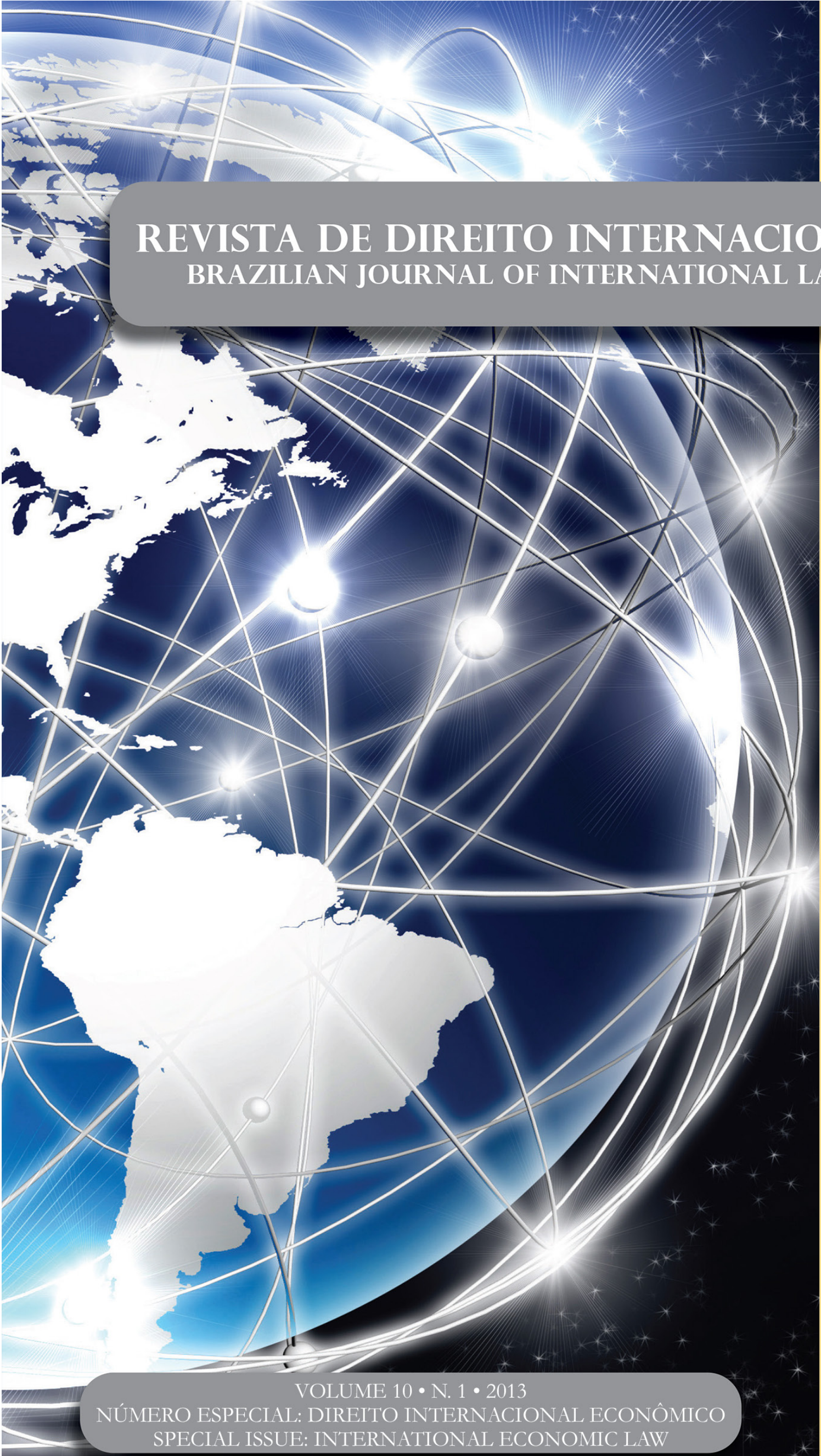

A defesa comercial e a restrição da liberalização e da integração comercial pelo aumento da alíquota de IPI de veículos importados no Brasil

Defense commercial and restriction of liberalization and commercial integration for increased rate of IPI vehicles imported in Brazil

Ricardo Serrano Osorio Clayton Couto 
Crônicas de direito internacional ............................................................. Julia Motte-Baumvol e Alice Rocha da Silva

BRAZILIAN TRADE POLICY IN HISTORICAL PERSPECTIVE: CONSTANT FEATURES, ERRATIC BEHAVIOR..11 Paulo Roberto de Almeida

Aspectos GEopolíticos do GAT'T E DA OMC .........................................................28 José Fontoura Costa

A REgulaÇÃo INTERNACIONAL dos SUbSídios AGRÍCOLAS: A CONTEMPORANEIDADE DO PARADIGMA REALISTA PARA A COMPREENSÃO DO SISTEMA DE COMÉRCIO AGRÍCOLA INTERNACIONAL VIGENTE

Natália Fernanda Gomes

ACORDO TRIPS: ONE-SIZE-FITS-ALL?

Tatianna Mello Pereira da Silva

É INTERESSANTE PARA O BRASIL ADERIR AO ACORDO SOBRE COMPRAS GOVERNAMENTAIS DA OMC?

Clarissa Chagas Sanches Monassa e Aubrey de Oliveira Leonelli

A Defesa COMERCIAL E A RESTRIÇÃo dA LIBERALIZAÇÃo E DA INTEGRAÇÃo COMERCIAL PELO AUMENTO DA ALÍQUOTA DE IPI DE VEÍCULOS IMPORTADOS NO BRASIL...................................86

Ricardo Serrano Osorio e Clayton Couto

A COOPERAÇÃo INTERNACIONAL NA DEFESA DA CONCORRÊNCIA

Vinicius Marques de Carvalho e Paulo Burnier da Silveira

Os ACORDOS DE COMÉRCIO PARA ALÉM DAS PREFERÊNCIAS: UMA ANÁLISE DA REGULAMENTAÇÃO SOBRE OS "NOVOS TEMAS" 105

Michelle Ratton Sanchez Badin e Lucas da Silva Tasquetto

INTEGRAÇÃO ECONÔMICA NO MERCOSUL: OPINIÕES CONSULTIVAS E A DEMOCRATIZAÇÃO NO ACESSO AO TRIBUNAL PERMANTE DE REVISÃO 128 Eduardo Biachi Gomes

"Fundos abutres" vs. Estados NaCionais: SObERANiA E ATUAÇÃo do Tribunal INTERNACIONAL do Direito do Mar a partir do Caso da Fragata libertad.. 138 Alexandre Pereira da Silva e Mariana Yante Barrêto Pereira

INVESTIMENTO ESTRANGEIRO: O PADRÃO DE TRATAMENTO JUSTO E EQUITATIVO E O PAPEL DA BOA-FÉ 
Fernando Santos Arenhart

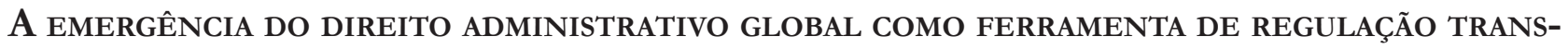
NACIONAL DO INVESTIMENTO ESTRANGEIRO DIRETO .................................................. 171

Andréa Rocha Postiga

Is INVESTMENT ARBITRATION AN APPROPRIATE VENUE FOR ENVIRONMENTAL ISSUES? A LATIN AMERICAN PERSPECTIVE.

Nitish Monebhurrun

A jurisprudência do Superior Tribunal de Justiça e a construção de um Conceito de

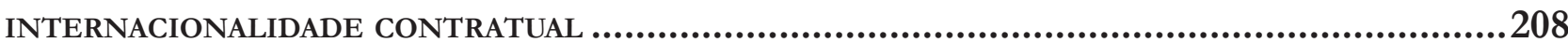

Frederico E. Z. Glitz

IMPACTO E INFLUÊNCIA DOS TRATADOS E CONVENÇÕES INTERNACIONAIS SOBRE A LEI BRASILEIRA DE ARBITRAGEM

Jamile Bergamaschine Mata Diz e Clarissa Correa Neto Ribeiro

A JURISPRUdÊNCIA NORTEAMERICANA E EUROPEIA SOBRE OS ACORDOS HORIZONTAIS E VERTICAIS: SUBSTRATO PARA ANÁLISE DA MATÉRIA NO BRASIL.

Daniel Amin Ferraz 


\title{
A defesa comercial e a restrição da liberalização e da integração comercial pelo aumento da alíquota de IPI de veículos importados no Brasil
}

\author{
Defense commercial and restriction of \\ liberalization and commercial integration \\ for increased rate of IPI vehicles imported in \\ Brazil*
}

Ricardo Serrano Osorio

Clayton Couto ${ }^{2}$

\footnotetext{
1 Mestre em Direito Ambiental pela Universidade de Caxias do Sul UCS, RS, Brasil (bolsista institucional). Mestrando em Direito Econômico e Socioambiental da Pontifícia Universidade Católica do Paraná, PUC/PR, Brasil (bolsista institucional). Possui especialização em Direito Corporativo e graduação em Direito pela USMP, Lima - Peru. Membro do "Centro de Estudios de Derecho de Minería, Energía y Recursos Hídricos" CEDEMIN. E-mail: richi27985@hotmail.com

2 Mestrando em Direito Econômico e Socioambiental pela Pontifícia Universidade Católica do Paraná, PUC/PR, Brasil (bolsista institucional). Possui graduação em Direito pela PUC/PR, Brasil. Advogado. E-mail: clayttoncouto@hotmail.com
}

* Recebido em 15/5/2013

Aprovado em 17/5/2013

\section{Resumo}

O presente artigo tem como objetivo analisar a evolução do comércio internacional e sua importância para a redução das barreiras tarifárias e o dinamismo da integração econômica a nível global. Para tanto, serão analisadas as rodadas comerciais realizadas no âmbito do GATT e a criação da OMC como momentos claves para alcançar a integração sinalada. Nesse sentido, nós nos focaremos a analisar o atual panorama da política de importação brasileira relacionado a tratar da medida de majoração das alíquotas do Imposto de Importação incidente sobre veículos importados, determinando que a defesa comercial brasileira atualmente infringe normas e princípios basilares de direito internacional econômico, restringindo assim a liberação e a integração comercial. Finalmente, chamamos a atenção aos agentes econômicos do comercio global que a atual política brasileira de defesa comercial é extremamente intervencionista gerando-se dessa forma uma insegurança jurídica nas transações comerciais.

Palavras-chave: Defesa comercial. GATT. Organização Mundial do Comércio. Rodadas comerciais. Liberalização e integração comercial . Decreto $7.567 / 2011$.

\section{Abstract}

This article aims to analyze the evolution of international trade and its importance to the reduction of tariff barriers and the dynamism of global economic integration. For this, we analyzed the trade rounds conducted under the GATT and the creation of the WTO as moments claves to achieve integration sinalada. Accordingly, we focus on analyzing the current policy landscape Brazilian import is related to the measure increased the rates of import duty levied on imported vehicles, determining that the Brazilian trade protection currently violates basic principles and norms of international economic law restricting thus the release and commercial integration. Finally, we draw attention to the economic agents of global trade that the current Brazilian policy of trade protection is highly interventionist generating 
up thus legal uncertainty in commercial transactions.

Keywords: Defense Trade. GATT. World Trade Organization. Trade rounds. Liberalization and trade integration. Decree 7.567/2011.

\section{INTRODUÇÃO}

Com o fim da Segunda Guerra Mundial, os países sentiram a necessidade de regular as relações econômicas internacionais, não só com o objetivo de melhorar a qualidade de vida de seus cidadãos, mas também por entenderem que os problemas econômicos influíam seriamente nas relações entre os Governos.

Entretanto, com o fracasso na criação da Organização Internacional do Comércio, ocasionada, principalmente, pela recusa dos Estados Unidos, os países assinaram o Acordo Geral de Tarifas e Comércio, criado para regular provisoriamente as relações comerciais internacionais.

Não obstante, o GATT foi o instrumento que, de fato, regulamentou por mais de quatro décadas as relações comerciais entre os países, sendo o responsável pela realização de oito rodadas comerciais, nas quais eram negociadas as reduções tarifárias e outras medidas de liberalização do comércio mundial.

Apesar das conquistas obtidas pelo GATT, a criação da Organização Mundial do Comércio, em 1994, conferiu maior certeza e segurança ao comércio mundial. Por outro lado, as normas contidas no GATT de 1947 foram ratificadas pela OMC.

Nesse contexto, infere-se que, desde a criação do GATT, o comércio mundial caminha rumo à redução de barreiras tarifárias e para uma segurança jurídica cada vez maior, no sentido de que as condutas adotadas pelos países devem estar em conformidade com as regras de comércio internacional vigentes, principalmente no âmbito da OMC.

Diante do exposto, o Decreto Federal no 7.567, de 15 de setembro de 2011, da Presidenta da República, estabeleceu uma majoração de alíquota de IPI para veículos importados, com o objetivo de proteger a indústria nacional automotiva.

No entanto, o ato contraria uma série de normas de direito econômico internacional, não obstante represente um contrassenso.

Diante do exposto, o presente artigo apresenta um panorama da evolução do comércio internacional, no sentido da liberalização econômica, passando desde a assinatura do GATT até a criação da OMC. Dentro dessa ótica, o estudo abrange a política econômica protecionista materializada na majoração da alíquota do IPI para veículos importados, analisando a medida sob a ótica das regras do GATT 1947, ratificado pela OMC

\section{A CRIAÇÃo do GATt NA PROCURA da LIBERA- ÇÃO E INTEGRAÇÃO COMERCIAL}

Embora a história do comércio se confunda com a história da evolução humana, é possível inferir que as bases e os fatores históricos que originaram a organização do comércio internacional atual se desencadearam, sobretudo, a partir do início do século XX. ${ }^{3}$

Consoante ressalta Welber Barral, até a década de 1930, o mundo atravessava um período de enorme intercâmbio comercial e de prosperidade econômica, que desencadeou crescente regulamentação comercial, sobretudo entre os países desenvolvidos. ${ }^{4}$

Entretanto, ese panorama foi drasticamente alterado com a crise da bolsa de Nova Iorque, seguindo-se um período marcado pela redução do comércio internacional, pelo descumprimento das regras comerciais e pelo agravamento da crise que acabou culminando na Segunda Guerra Mundial. ${ }^{5}$

No final da Segunda Guerra, enormes dificuldades econômicas ameaçaram todo o sistema financeiro e comercial mundial, que já se encontrava desgastado pelos fatores que precederam o conflito. ${ }^{6}$

O flagelo da Segunda Guerra tornou evidente a necessidade da cooperação, com a criação de uma estrutura política que pudesse garantir a paz, e de uma estrutu-

BARRAL, Welber. O comércio internacional. Belo Horizonte: Del Rey, 2007. p. 25.

${ }^{4}$ BARRAL, Welber. O comércio internacional. Belo Horizonte: Del Rey, 2007 p. 26.

5 BARRAL, Welber. O comércio internacional. Belo Horizonte: Del Rey, 2007 p. 26.

6 AMARAL, Antonio Carlos Rodrigues do (Coord.). Direito do comércio internacional: aspectos fundamentais. 2. ed. São Paulo: Lex, 2006. p. 81. 
ra econômica que pudesse evitar a instabilidade. ${ }^{7}$ Nesse contexto, iniciaram-se as articulações para construir um mundo mais seguro, o que ensejaria o reforço da cooperação internacional. Esse intuito se refletiu na criação da Organização das Nações Unidas (ONU), à qual foram conferidos mecanismos de solução de conflitos e de possibilidade de intervenção muito superiores ao do frustrado intento anterior, da Liga das Nações. ${ }^{8}$

No plano econômico, a discussão para reestruturação ocorreu em Bretton Woods, em 1944, com a reunião dos representantes das potências ocidentais.

Influenciada pela política econômica defendida por John Maynard Keynes, a reunião de Bretton Woods chegou ao consenso de que era necessário criar instituições multilaterais que promovessem a cooperação e a estabilidade nas relações econômicas internacionais. ${ }^{9}$

Nesse sentido, surgiram as bases iniciais para a criação do Fundo Monetário Internacional (FMI), do Banco Internacional para a Reconstrução e Desenvolvimento (BIRD ou Banco Mundial), e da Organização Internacional do Comércio (OIC).

As discussões que se seguiram a Bretton Woods originaram a Carta de Havana. A primeira parte do documento tratava da criação da OIC, enquanto a segunda e terceira partes estipulavam regras de redução de tarifas e do processo a seguir seguido para a implantação dessas regras. ${ }^{10}$

Todavia, o projeto da criação da Organização Internacional do Comércio, nos moldes propostos em Bretton Woods se mostrava deveras audacioso, na medida em que propunha uma organização multilateral que abarcava uniformização das regras comerciais, a promoção do comércio, do desenvolvimento e do pleno emprego. ${ }^{11}$ A par disso, o Congresso dos Estados Unidos

BARRAL, Weber. O comércio internacional. Belo Horizonte: Del Rey, 2007 p 26.

8 BARRAL, Weber. O comércio internacional. Belo Horizonte: Del Rey, 2007 p. 27.

9 BARRAL, Weber. O comércio internacional. Belo Horizonte: Del Rey, 2007. p. 27.

${ }^{10}$ A preocupação com tarifas era recorrente à época, tendo em vista que o aumento de tarifas sobre a importação de bens estrangeiros tinha sido uma constante durante o período de crise econômica, funcionando como mecanismo de arrecadação fiscal do esforço de guerra. BARRAL, Welber. O comércio internacional. Belo Horizonte: Del Rey, 2007 p. 29.

11 AMARAL, Antonio Carlos Rodrigues do (Coord.). Direito do comércio internacional: aspectos fundamentais. 2. ed. São Paulo: Lex, 2006. p. 82. não aprovou a ratificação da Carta de Havana, no que se referia à criação da OIC.

Para Welber Barral, a recusa estadunidense foi motivada por um conjunto de fatores, representando um comportamento dúbio em relação à cooperação internacional. Nesse contexto, explica Barral: ${ }^{12}$

Naquele ano de 1948, houve uma mudança na composição do Congresso e uma maioria republicana passou a contrariar o democrata Truman. Além disso, ressurgia nos Estados Unidos o discurso do isolacionismo, que de tempos em tempos ganha relevância na prática política norteamericana. Mais que isto, os Estados Unidos, potência incontestável à época, temiam o poder, julgado excessivo, que se outorgava à OIC, porque poderia reduzir a autonomia norte-americana na defesa de seus interesses.

Como consequência da recusa do Congresso dos Estados Unidos, os demais signatários da Carta de Havana perderam o interesse em seguir com sua ratificação, uma vez que, sem a participação da maior potência comercial, de nada adiantaria uma organização para regulamentar o comércio internacional. ${ }^{13}$

Consequentemente, a Organização Internacional do Comércio nunca chegou a ser criada de fato; apenas a segunda e terceira partes da Carta de Havana entraram em vigor em $1^{\circ}$ de janeiro de 1948, formando o Acordo Geral de Tarifas e Comércio (GATT - sigla do inglês General Agreement on Tariffs and Trade), um protocolo provisório constituído por um conjunto de normas direcionadas para a redução das tarifas alfandegárias no comércio internacional. ${ }^{14}$

O Acordo possuía quatro partes: a primeira, composta pelos dois artigos que regulavam o funcionamento multilateral da cláusula da nação mais favorecida e as provisões

12 BARRAL, Welber. O comércio internacional: aspectos fundamentais. 2. ed. São Paulo: Lex, 2006. p. 29. Acerca da recusa dos Estados Unidos em anuir à criação da OIC, Antonio Carlos Rodrigues do Amaral destaca que "[...] o protecionismo contra o qual os Estados unidos e a Inglaterra levantaram suas bandeiras no pós-guerra foi por eles mesmos largamente praticado durante todas as décadas que se seguiram ao GATT-1947 até o presente. Embora muito se tenha avançado em termos de liberalização, muitas vezes o argumento do laissez faire foi mais um recurso retórico para incentivar a abertura de mercados dos demais países do que, paradoxalmente, os de seus principais defensores". AMARAL, Antonio Carlos Rodrigues do (Coord.). Direito do comércio internacional: aspectos fundamentais. 2. ed. São Paulo: Lex, 2006. p. 57.

13 BARRAL, Weber. O comércio internacional. Belo Horizonte: Del Rey, 2007. p. 29.

14 BARRAL, Welber. De Bretton Woods a Doha. In: BARRAL, Welber (Coord.). O Brasile a OMC. 2. ed. Curitiba: Juruá, 2003, p. 13. 
sobre as concessões tarifárias; a segunda (arts. $3^{\circ}$ a 23), com o código de conduta comercial do GATT; a terceira (arts. 24 a 35), estabelecendo procedimentos sobre o funcionamento do acordo, além de importantes dispositivos de caráter substancial. Posteriormente, atendendo à pressão dos países em desenvolvimento, foi adicionada uma quarta parte, relativa ao comércio e desenvolvimento. ${ }^{15}$

Segundo Ricardo Seitenfus, o GATT deve ser considerado como sendo uma organização internacional especial na medida em que possui duas faces distintas: por um lado, apresenta cunho jurídico, eis que se trata de um rol de normas procedimentais sobre as relações comerciais entre os Estados-Partes. Por outro lado, trata-se de um fórum de negociação comercial no qual, por meio, de instrumentos próprios à diplomacia parlamentar, de natureza comercial, procura-se aproximar posições entre os Estados-Partes. Essa face é de natureza essencialmente política. ${ }^{16}$

Para Welber Barral, a estrutura jurídica que entrou em vigor em 1948, após o fracasso da constituição da OIC era "capenga e provisória", e a ela faltava o pilar da organização internacional. ${ }^{17}$

A despeito de ter sido criado para vigorar provisoriamente, até que se criasse uma organização multilateral relativa ao comércio, o GAT'T vigorou por quase meio século.

\section{DECISÕES E BARREIRAS TARIFÁRIAS COMERCIAIS: A PROPÓSITO DA CLÁUSULA DA NAÇão MAIS FAVO- RECIDA E O PRINCÍPIO DO TRATAMENTO NACIONAL}

Com vistas a garantir a contínua liberalização do comércio internacional, os 23 Estados signatários iniciais do GATT (incluindo o Brasil), acordaram os princípios basilares que deveriam ser observados nas relações comerciais: a cláusula da nação mais favorecida e o princípio do tratamento nacional. ${ }^{18}$

\footnotetext{
15 AMARAL, Antonio Carlos Rodrigues do (Coord.). Direito do comércio internacional: aspectos fundamentais. 2. ed. São Paulo: Lex, 2006. p. 57-58.

16 SEITENFUS, Ricardo. Manual das Organizações Internacionais. 2. ed. Porto Alegre: Livraria do Advogado, 2000. p. 160.

17 BARRAL, Weber. O comércio internacional. Belo Horizonte: Del Rey, 2007.

p. 29-30.

18 BARRAL, Weber. O comércio internacional. Belo Horizonte: Del
}

Pela cláusula da nação mais favorecida, um país se compromete a estender a outro país com o qual tenha firmado um acordo comercial condições tão favoráveis quanto às que venha posteriormente a contratar com um terceiro país. ${ }^{19}$ Essa cláusula representou importante mecanismo para a fluidez do comércio internacional, tendo em vista que as reduções tarifárias alcançadas nas negociações bilaterais também eram estendidas às demais Partes Contratantes do GATT.

Por sua vez, o princípio do tratamento nacional estabelecia que as Partes Contratantes não poderiam discriminar o produto importado com outras medidas além da aplicação da tarifa negociada entre os signatários.

Em outros termos, uma vez que o produto importado pagou a tarifa compromissada, no momento de sua entrada no mercado nacional, ele não mais pode ser discriminado. A discriminação, proibida pelo princípio do tratamento nacional, tanto pode se referir à diferenciação tributária ou a outras medidas discriminatórias contra o produto estrangeiro. ${ }^{20}$

Tal regra se mostrou de enorme importância, eis que, conforme discorre Welber Barral, "[...] de nada adiantaria negociar baixas tarifas, para depois exigir impostos diferenciados ou licenças especiais que inviabilizassem a revenda do produto importado ao consumidor nacional". ${ }^{21}$

As barreiras tarifárias, como a própria nomenclatura sugere, atuam por meio da adoção de tarifas aduaneiras sobre os produtos importados, aumentando o preço dele e incentivando o consumo de produtos nacionais. A adoção ou majoração de tributos incidentes sobre a importação de mercadorias encarece os produtos im-

Rey, 2007.p. 30.

19 AMARAL, Antonio Carlos Rodrigues do (Coord.). Direito do comércio internacional: aspectos fundamentais. 2. ed. São Paulo: Lex, 2006. p. 56. No mesmo sentido, Welber Barral lembra que a cláusula da nação mais favorecida já existia em acordos bilaterais, a exemplo do Tratado de Comércio e Navegação, entre Inglaterra e Portugal, quando da vinda da família real portuguesa para o Brasil, em 1808, onde se previa que qualquer vantagem concedida por Portugal a outros Estados se estenderia automaticamente aos produtos ingleses e vice-versa. BARRAL, Welber. O comércio internacional. Belo Horizonte: Del Rey, 2007.p. 31.

20 BARRAL, Welber. O Comércio Internacional. Belo Horizonte: Del Rey, 2007. p.60.

${ }^{21}$ Ressalte-se que, além dos dois princípios basilares, uma série de exceções também compunha o GATT. Tais exceções fundamentavam-se tanto em situações que configurariam "comércio injusto" como as que justificariam "barreiras legítimas". BARRAL, Welber. $O$ comércio internacional. Belo Horizonte: Del Rey, 2007. p. 31. 
portados, diminuindo sua competitividade em face dos produtos nacionais. ${ }^{22}$

Diverso disso, as barreiras não tarifárias abrangem uma gama variada de medidas, com o intuito de restringir o acesso dos produtos importados ao mercado nacional. As barreiras não tarifárias podem impedir a importação, impor limites máximos, quotas de importação, ou ainda estabelecer exigências adicionais aos produtos estrangeiros, encarecendo sua importação. São exemplos de barreiras não tarifárias, as barreiras técnicas e as barreiras fitossanitárias, dentre outras. ${ }^{23}$

Nesse contexto, após a tumultuada criação do GATT, sua evolução ocorreu no âmbito das rodadas de negociação, nas quais os representantes dos países signatários se reuniam para negociar a redução de barreiras tarifárias e não tarifárias.

As primeiras rodadas comerciais do GATT (Rodada Genebra, em 1947; Rodada Annecy, em 1949; Rodada Torquay, em 1951; Rodada Genebra, em 1956; Rodada Dillon, em 1960-1961), serviram fundamentalmente para negociar a redução de tarifas. ${ }^{24}$

Consequentemente, foram se incorporando ao GATT outros Estados signatários e o rol de temas tratados nas rodadas comerciais também se alargando, abrangendo outras barreiras ao comércio internacional. Dentro dessa perspectiva, nas rodadas comerciais Kennedy (19641967), Tóquio (1973-1979) e Uruguai (1986-1994), novos acordos foram sendo negociados, em temas como medidas antidumping e medidas compensatórias. ${ }^{25}$

Destarte, apesar das falhas estruturais do GATT, já em 1950 os níveis tarifários despencaram de 40\% para $25 \%{ }^{26}$ A progressiva redução dos entraves tarifários e

\footnotetext{
22 TOMAZETTE, Marlon. Comércio internacional \& medidas antidumping. Curitiba: Juruá, 2008. p. 30. No mesmo sentido, Welber Barral explica que o termo "tarifa", no comércio internacional, refere-se a "[...] qualquer imposição governamental (impostos, taxas, contribuições) sobre a importação de produtos estrangeiros.”. Neste contexto, quanto maior a tarifa aplicada, mais caro e pouco competitivo se tornará o produto importado, gerando-se uma vantagem, em termos de preço, para o produto nacional e prejudicando o fluxo internacional de mercadorias. BARRAL, Welber. O comércio internacional. Belo Horizonte: Del Rey, 2007. p. 30.

23 TOMAZETTE, Marlon. Comércio internacional \& medidas antidumping. Curitiba: Juruá, 2008. p. 30.

24 BARRAL, Welber. O comércio internacional. Belo Horizonte: Del Rey, 2007. p. 31.

25 BARRAL, Welber. De Bretton Woods a Doha, p. 13.

26 AMARAL, Antonio Carlos Rodrigues do (Coord.). Direito do comércio internacional: : aspectos fundamentais. 2. ed. São Paulo: Lex,
}

não tarifários contribuiu para um sensível incremento do comércio mundial, especialmente no caso dos países industrializados. Durante o período 1950-90, a produção bruta mundial foi multiplicada por quatro, e o comércio mundial, por dezesseis. ${ }^{27}$

Nesse contexto, desde a criação do GATT, as barreiras tarifárias têm sofrido progressiva redução e a expectativa é de que sejam reduzidas ainda mais. ${ }^{28}$

Entretanto, é interessante notar como as reduções tarifárias foram sendo acompanhadas pelo crescimento de barreiras não tarifárias ao comércio internacional. Para Welber Barral, isso permite afirmar que o protecionismo ${ }^{29}$ não é, como se pensa comumente, uma antítese do livre comércio; ao revés, o protecionismo é uma consequência lógica da liberalização comercial.

Em outros termos, cada vez que aumenta a concorrência estrangeira, os produtores nacionais esperneiam por proteção; quando essa proteção não mais pode se materializar em tarifas - a não ser violando obrigações internacionais - as barreiras não tarifárias surgem como uma alternativa viável. ${ }^{30}$

\section{A CONSOLIDAÇÃo do GATT MEDIANTE A CRIAÇÃO DO OMC.}

É inegável a contribuição do GATTT para o desenvolvimento do comércio internacional e para a integra-

2006. p. 58.

27 SEITENFUS, Ricardo. Manual das Organizações Internacionais. 2. ed. Porto Alegre: Livraria do Advogado, 2000, p. 165.

28 REBONO, Maria. Introdução ao Comércio Internacional. In: SEGRE, German. Manual prático de comércio exterior. São Paulo: Atlas, 2006 , p. 31.

29 Segundo Welber Barral, o protecionismo pode ser entendido como "[...] a utilização de medidas visando à modificação de um fluxo comercial, geralmente buscando favorecer produtores nacionais". BARRAL, Welber. Protecionismo e neoprotecionismo no comércio internacional. In: (Org.). O Brasil e o protecionismo. São Paulo: Aduaneiras, 2002. p. 14. No mesmo sentido, Marlon Tomazette explica que o protecionismo envolve a adoção de medidas que alteram o desenvolvimento normal da atividade comercial, afetando determinados comerciantes, normalmente estrangeiros, em detrimento de outros, normalmente nacionais. TOMAZETTE, Marlon. Comércio internacional \& medidas antidumping. Curitiba: Juruá, 2008. p. 30.

30 BARRAL, Welber. O comércio internacional. Belo Horizonte: Del Rey, 2007. p. 32. Neste contexto, Maria Rebono lembra que países desenvolvidos, como os Estados Unidos, Japão e a União Europeia mantém barreiras não tarifárias que dificultam a entrada de produtos brasileiros em seus mercados. REBONO, Maria. Introdução ao Comércio Internacional, p. 30. 
ção econômica, à vista da redução das barreiras tarifárias e não tarifárias negociadas ao longo das rodadas comerciais. Consoante expõe Antonio Carlos Rodrigues do Amaral, apesar de, a partir de 1980, deixar de ser tão compatível com as realidades do comércio mundial, o sucesso do GATTT e, por consequência, do sistema multilateral de negociações, é incontestável. As contínuas reduções tarifárias proporcionaram um enorme crescimento no comércio internacional, fazendo que cada vez mais países procurassem aderir ao GAT'T, principalmente na Rodada Uruguai. ${ }^{31}$

Entretanto, o GATT apresentava algumas limitações que reduziam o grau de segurança jurídica e fortaleciam o aspecto diplomático negocial. Uma dessas limitações se referia aos painéis, mecanismo adotado pelo GATT para solução de controvérsias cujo relatório poderia ser bloqueado por quaisquer das partes, inclusive pelo Estado vencido na demanda. ${ }^{32}$

Ademais, vigorava até então o denominado "GATT à la carte", segundo o qual as Partes Contratantes não eram obrigadas a aderir a esses novos acordos. Consoante explica Barral, esse sistema criava uma situação extremamente complexa, em que os países eram partes do GATTT, mas podiam não ser parte dos acordos complementares. ${ }^{33}$

Não obstante, a complexidade jurídica do GATT foi agravada pelo contexto político da década de 1970, no auge da Guerra Fria, que coincidiu com medidas unilaterais dos Estados Unidos, ao tempo em que os países em desenvolvimento buscavam maior autonomia política e econômica em relação às duas potências nucleares. Tal cenário contribui para a retomada de discussões na tentativa de consolidar uma organização internacional alternativa ao GATT. ${ }^{34}$

Todos esses problemas foram invocados no início da última rodada de negociações ocorridas no âmbito do GATT', no Uruguai, em 1986.

A Rodada Uruguai durou seis anos, o dobro do previsto. Quando foi concluída, em 1994, com a assinatura da Ata Final em Marrakech, os textos negociados e seus anexos compunham 26.000 páginas de regras, abordan-

\footnotetext{
31 AMARAL, Antônio Carlos Rodrigues do. Direito do Comércio Internacional: aspectos fundamentais. 2. ed. São Paulo: Lex Editora, 2006, p. 85 .

32 BARRAL, Welber. O Brasil e a OMC, p. 14.

33 BARRAL, Welber. O comércio internacional. Belo Horizonte: Del Rey, 2007. p. 33.

34 BARRAL, Welber. O comércio internacional. Belo Horizonte: Del Rey, 2007. p. 33.
}

do os mais diversos temas, e envolvendo a maior parte do comércio internacional. ${ }^{35}$

Além da redução considerável de tarifas e do aperfeiçoamento dos instrumentos de defesa comercial, a Rodada Uruguai culminou na criação da Organização Mundial do Comércio (OMC), que iniciou suas atividades em $1^{\circ}$ de janeiro de 1995.

A grande inovação da OMC foi a constituição do Órgão de Solução de Controvérsias, sistema decisório mais eficaz que o existente no âmbito do GAT'T. Diverso do que ocorria no âmbito do GATT, o Órgão de Solução de Controvérsias apresenta estrutura complexa, com prazos definidos para a constituição e funcionamento dos painéis e a elaboração dos relatórios, bem como para a apresentação de defesa e de apelação. Não obstante, o Estado vencido é obrigado a oferecer uma compensação ou ajustar a sua política comercial ao relatório aprovado. ${ }^{36}$

\section{Adefesa COMERCIAL bRASILEIRA MEDIANTE A MAJORAÇÃO DA ALÍQUOTA DO IPI DE VEÍCULOS IMPORTADOS.}

O Decreto $\mathrm{n}^{\circ}$ 7.567, de 15 de setembro de 2011, estabeleceu novos critérios para a redução das alíquotas do Imposto sobre Produtos Industrializados em favor da indústria automotiva.

Na prática comercial, com a alteração estabelecida pelo Decreto $n^{0} 7.567$, a redução das alíquotas do IPI para veículos restou condicionada ao atendimento de uma série de requisitos, entre eles, a exigência de fabricação de veículos referidos no Anexo I do Decreto com, no mínimo, sessenta e cinco por cento de conteúdo regional médio para cada empresa, e a realização de pelo menos seis das seguintes atividades, no País, pela empresa beneficiária, por empresa por ela contratada para esse objetivo específico ou, ainda, por fornecedora da empresa beneficiária, em pelo menos oitenta por cento de sua produção de veículos: montagem, revisão final e ensaios compatíveis; estampagem; soldagem; tratamento anticorrosivo e pintura; injeção de plástico; fabricação de motores; fabricação de transmissões; montagem de sistemas de direção, de suspensão, elétrico e de

\footnotetext{
35 BARRAL, Welber. O Brasil e a OMC, p. 15.

${ }^{36}$ A título elucidativo, Welber Barral expõe que o Brasil é usuário frequente do sistema de solução de controvérsias da OMC, sobretudo na condição de reclamado. BARRAL, Welber. O Brasil e a $O M C$, p. 18.
} 
freio, de eixos, de motor, de caixa de câmbio e de transmissão; montagem de chassis e de carrocerias; montagem final de cabines ou de carrocerias, com instalação de itens, inclusive acústicos e térmicos, de forração e de acabamento; e produção de carrocerias preponderantemente por meio de peças avulsas estampadas ou formatadas regionalmente.

Em outros termos, a partir da entrada em vigor do Decreto 7.567, os veículos importados que se enquadrem nos critérios contidos no Anexo I passaram a ter alíquota 30\% superior no IPI, se comparado aos veículos produzidos em território nacional.

Entretanto, a majoração não se aplica aos veículos procedentes dos países membros do Mercosul, além do México, por força do Acordo de Complementação Econômica $n^{\circ} 55$, firmado entre o Mercosul e México.

O Decreto no 7.567 entrou em vigor em 16.09.2011. No entanto, o Supremo Tribunal Federal, apreciando ação direta de inconstitucionalidade, deferiu medida liminar para suspender o artigo 16 do Decreto, que conferia vigência imediata à majoração de alíquotas sobre operações envolvendo veículos automotores, sob o fundamento de que "[...] a majoração da alíquota do IPI, passível de ocorrer mediante ato do Poder Executivo - artigo 153, $\int 1^{\circ}$-, submete-se ao princípio da anterioridade nonagesimal previsto no artigo 150, inciso III, alínea "c", da Constituição Federal". ${ }^{37}$

Nesses termos, após a suspensão, as regras que majoraram o IPI de veículos importados voltaram a vigorar em 16.12.2011.

A medida que cria barreira tarifária à entrada de veículos importados no Brasil, visando reduzir o volume de importações de veículos, de modo a "evitar a exportação de empregos industriais", é reflexo da política protecionista adotada pelos últimos governos brasileiros ante a crise econômica mundial. ${ }^{38}$

Relativo à política de importações do Brasil, notou-se no início da década de 1970 um processo de liberalização das importações, incrementado, notadamente, pelo chamado "milagre brasileiro". Entretanto, com a crise mundial do petróleo, o comércio internacional, em seu todo, viu-se am-

\footnotetext{
37 BRASIL. Supremo Tribunal Federal. Ação direta de inconstitucionalidade $n^{\circ}$ 4661. Relator Ministro Marco Aurélio. Data do julgamento: 28.10.2011. Publicação no DJe: 23.03.2012.

38 RODRIGUES, Azelma. Carro sem conteúdo nacional pode pagar até 55\% de IPI. In: Jornal Valor Econômico. Disponível em: <http:// www.valor.com.br/empresas/1008502/carro-sem-conteudo-nacional-pode-pagar-ate-55-de-ipi. >. Acesso em:5 jun.2012.
}

plamente prejudicado diante da criação dos mais diversos mecanismos protecionistas, somados aos já existentes. ${ }^{39}$

O Brasil, por seu turno, lançou mão de determinados expedientes igualmente protecionistas, visando, de um lado, rígido controle das importações em face da conjuntura (prevenção da evasão de divisas e favorecimento do controle da dívida externa) e, de outro, a substituição das importações, objetivando o fortalecimento de seu parque industrial. ${ }^{40}$

Contudo, no final da década de 1980, observou-se uma crescente tendência liberalizante da política de comércio exterior brasileiro, motivada pela necessidade de adequação dessa política à configuração que o parque industrial implantando tinha assumido nos últimos anos, assim como em face dos compromissos internacionais assumidos pelo País. Nesse sentido, na linha do que expõe João dos Santos Bizelli, parte considerável dos mecanismos restritivos anteriormente alinhados foi extinta e outras medidas foram tomadas para que as operações de importações fossem conduzidas com o mínimo de intervenção estatal. ${ }^{41}$

Nos últimos tempos, entretanto, desde que a crise econômica mundial ganhou nova intensidade, o Brasil voltou a adotar forte política protecionista, impondo restrições às importações. ${ }^{42} \mathrm{O}$ aumento da alíquota do IPI de veículos importados é uma dessas restrições.

Nesse ínterim, a majoração da alíquota do IPI para veículos importados engendra discussões em torno da observância das regras de comércio internacional vigentes, além das questões relativas ao direito tributário, ${ }^{43}$ que não são

39 BIZELLI, João dos Santos. Noções básicas de importação. 8. ed. São Paulo: Aduaneiras, 2001. p. 14.

40 portação. 8. ed. São Paulo: Aduaneiras, 2001. p. 14.

${ }^{41}$ BIZELLI, João dos Santos. Noções básicas de importação. 8. ed. São Paulo: Aduaneiras, 2001. p. 14

${ }^{42}$ MOREIRA, Assis. Brasil contesta acusações de protecionismo feitas pela OMC. In: Jornal Valor Econômico. Disponível em: <http:// www.valor.com.br/brasil/2756216/brasil-contesta-acusacoes-deprotecionismo-feitas-pela-omc >. Acesso em: 19 de julho de 2012.

43 Embora o IPI possua natureza extrafiscal, no sentido de que possui finalidades além da mera arrecadação, não pode ser utilizado para inibir importações. O tributo competente para tal preceito é o Imposto de Importação, consoante dispõe o artigo 21 do Código Tributário Nacional: "Art. 21. O Poder Executivo pode, nas condições e nos limites estabelecidos em lei, alterar as alíquotas ou as bases de cálculo do imposto [de importação], a fim de ajustá-lo aos objetivos da política cambial e do comércio exterior." Ademais, consoante destaca Hugo de Brito Machado, esta possibilidade de alteração de alíquota pelo Poder Executivo só deve se concretizar em circunstâncias especiais que a justifiquem, e ainda assim, restritas aos limites estabelecidos em legislação ordinária. Não obstante, as alterações de alíquotas, como ato administrativo que são, devem 
objeto deste estudo.

A seu turno, a imposição de barreira tarifária para veículos importados por meio da majoração da alíquota do IPI não observou aos princípios e normas basilares do direito econômico internacional, notadamente aqueles contidos no GATT 1947 e ratificados com a criação da OMC.

A par disso, a política de proteção da indústria automotiva, nos moldes expostos no Decreto 7.567 , viola o princípio do tratamento nacional, um dos pilares do comércio internacional. O artigo $3^{\circ}$, II do Acordo Geral de Tarifas Aduaneiras e do Comércio de 1994, que ratificou o GATT 1947, dispõe que [...] "os produtos do território de qualquer Parte Contratante, importados por outra Parte Contratante, não estão sujeitos, direta ou indiretamente, a impostos ou outros tributos internos de qualquer espécie superiores aos que incidem, direta ou indiretamente, sobre produtos nacionais".

Consoante exposto alhures, tal princípio do tratamento nacional veda a discriminação do produto importado com outras medidas além da aplicação da tarifa negociada entre os signatários, assegurando que o produto importado, após ingresso no país, tenha o mesmo tratamento concedido ao produto nacional.

Segundo esclarece Rabih Ali Nasser, essa regra se aplica depois que o produto importado está no país. O princípio, diz o jurista, não se aplica aos impostos incidentes sobre a importação da mercadoria, cuja redução é objeto de outras normas do Sistema Multilateral de Comércio. O tratamento nacional passa a valer uma vez que o produto tenha sido internalizado, mesmo porque não se poderia falar em tratamento igual no que se refere a tarifas de importação, pois elas não incidem sobre os produtos nacionais. ${ }^{44}$ Diante do exposto, a majoração da alíquota de IPI para veículos importados não observou o princípio do tratamento nacional, à medida que estabeleceu barreira ao produto importado, depois de internalizado.

Não obstante, as exceções ao livre comércio podem ser agrupadas em três classes, medidas de defesa comercial (salvaguardas, medidas compensatórias, medidas antidumping); exceções permanentes (exceções gerais,

conter a motivação bem fundamentada do uso da extrafiscalidade. MACHADO, Hugo de Brito. Comentários ao Código Tributário Nacional. São Paulo: Atlas, 2003. p. 299.

44 NASSER, Rabih Ali. A liberalização do comércio internacional nas normas do GATT - OMC. São Paulo: Ltr, 1999, p. 72. waivers, razões de segurança nacional e renegociação de concessões) e exceções contingenciais (exceções da balança de pagamentos e exceção da indústria nascente). Todas essas exceções são regulamentadas por regras de um sistema multilateral de comércio, a fim de evitar discriminações e a imposição de restrições veladas ao livre comércio. ${ }^{45}$

A política do governo brasileiro de aumentar a alíquota do IPI para veículos importados, com vistas a diminuir a importação e assim, favorecer a indústria nacional, assemelha-se às medidas de salvaguardas de que trata o GATT de 1947.

Segundo Maria Rebono, as salvaguardas são medidas de "urgência" contra as importações de determinados produtos. Independentemente de sua procedência, são aplicadas para prevenir ou reparar o dano e salvaguardar a indústria nacional. Essas medidas são aplicadas quando as importações no território do país importador aumentam substancialmente em quantidades que podem causar dano ou ameaçar gravemente o setor de produção nacional que fabrica produtos similares ou diretamente concorrentes. ${ }^{46}$

Todavia, a adoção de uma medida de salvaguarda exige a observância de uma série de regras elencadas no Acordo sobre Salvaguardas, entre elas a necessidade prévia de investigação.

Com efeito, o artigo $2^{\circ}$ do Acordo sobre Salvaguardas prevê que um membro só poderá aplicar uma medida de salvaguarda a um produto após haver determinado que as importações daquele produto em seu território tenham aumentado em quantidades tais que causam ou ameaçam causar prejuízo grave ao setor nacional que produz bens similares ou diretamente concorrentes.

Por sua vez, o artigo $3^{\circ}$ dispõe que os membros só poderão aplicar uma medida de salvaguarda “[...] após investigação conduzida por suas autoridades competentes de conformidade com procedimentos previamente estabelecidos e tornados públicos nos termos do Artigo X do GATT 1994".

$\mathrm{O}$ aludido artigo estabelece ainda o procedimento necessário para adoção de salvaguarda, que compreende

\footnotetext{
45 TOMAZETTE, Marlon. Comércio internacional \& medidas antidumping, p. 39.

46 REBONO, Maria. Introdução ao Comércio Internacional. In: SEGRE, German. Manual prático de comércio exterior. São Paulo: Atlas, 2006. p. 28-29.
} 
a publicação de um aviso destinado a informar razoavelmente todas as partes interessadas, assim como audiências públicas ou outros meios idôneos pelos quais os importadores, os exportadores e outras partes interessadas possam apresentar provas e expor suas razões, e ter ainda a oportunidade de responder à argumentação das outras partes e apresentar suas opiniões, inclusive, entre outras coisas, sobre se a aplicação da medida de salvaguarda seria ou não do interesse público.

Tem-se, entretanto, que o governo brasileiro não observou tais procedimentos ao impor a barreira tarifária em discussão, eis que não ocorreu a investigação prévia para verificação do prejuízo ou risco de prejuízo grave ao setor nacional, nos termos do Acordo sobre Salvaguardas.

Ademais, qualquer que seja o tipo de medida protecionista adotada, ela tem que se justificar, uma vez que a sua adoção acaba prejudicando os consumidores que teriam acesso a mais produtos e com preços melhores. ${ }^{47}$

Nesses termos, ao adotar a majoração da alíquota do IPI para veículos importados, o governo brasileiro não apresentou justificativa fundamentada, segundo as regras estabelecidas pela OMC.

\section{Conclusões}

O tema analisado, por tratar de matéria complexa, permite um sem-número de conclusões cabíveis. Apresentam-se, pois, algumas premissas que se destacam, à luz do direito econômico internacional.

De início, imperativo reconhecer a importância do GATT 1947 como mecanismo de desenvolvimento do comércio internacional e indutor da liberalização comercial. Entretanto, a criação da OMC representou um avanço ainda maior na expansão econômica internacional, principalmente por que conferiu maior certeza e segurança ao comércio mundial, ao adotar mecanismos de controle das políticas econômicas, inclusive com a possibilidade de aplicação de sanções.

\footnotetext{
47 As justificativas para a adoção de medidas protecionistas envolvem basicamente a proteção do emprego, a proteção à indústria nacional incipiente e a manutenção de estruturas socioculturais, ou ainda a proteção ao consumidor. Tais justificativas são apresentadas pelos defensores de tais medidas, o que não significa que elas sejam realmente aceitáveis. TOMAZETTE, Marlon. Comércio internacional \& medidas antidumping, op. cit., p. 30-32.
}

Verifica-se, pois, que a política de aumento da alíquota do imposto sobre produtos industrializados para veículos importados, nos termos do Decreto n 7.567 não observou as regras de comércio internacional estabelecidas no âmbito da Organização Mundial do Comércio, notadamente o princípio do tratamento nacional e da não discriminação, além de não ter sido obedecido o procedimento estabelecido pelo Acordo sobre Salvaguardas para a adoção de tal medida.

Infere-se, por conseguinte, que o Brasil pode ser responsabilizado com sanções perante a OMC pela prática de tal medida, inobstante os reflexos negativos causados no cenário econômico internacional.

Nessa linha, ressalte-se que o governo brasileiro poderia ter adotado outras medidas que têm o condão de atingir a mesma finalidade. A majoração da alíquota do Imposto de Importação dos veículos, tributo destinado a regular o comércio exterior, é exemplo de política que não fere o princípio do tratamento nacional e se presta a frear a entrada de veículos importados.

Ao ocaso, diante da situação fática analisada no presente estudo, acentua-se a importância da consolidação das regras de direito econômico, como eixo conformador das relações econômicas internacionais.

\section{REFERÊNCIAS}

AMARAL, Antonio Carlos Rodrigues do (Coord.). Direito do comércio internacional: aspectos fundamentais. 2. ed. São Paulo: Lex, 2006.

BARRAL, Welber. De Bretton Woods a Doha. In: BARRAL, Welber (Coord.) O Brasil e a OMC. 2. ed. Curitiba: Juruá, 2003.

BARRAL, Welber. O comércio internacional. Belo Horizonte: Del Rey, 2007.

BARRAL, Welber. Protecionismo e noeprotecionismo no comércio internacional. In: .(Org.). O Brasile o protecionismo. São Paulo: Aduaneiras, 2002.

BIZELLI, João dos Santos. Noções básicas de importação 8. ed. São Paulo: Aduaneiras, 2001.

BRASIL. Supremo Tribunal Federal. Ação direta de inconstitucionalidade $n^{\circ}$ 4661. Relator Ministro Marco Aurélio. Data do julgamento: 28.10.2011. Publicação no DJe: 23.03.2012. 
MACHADO, Hugo de Brito. Comentários ao Código Tributário Nacional. São Paulo: Atlas, 2003.

MOREIRA, Assis. Brasil contesta acusações de protecionismo feitas pela OMC. Jornal Valor Econômico. Disponível em: <http://www.valor.com.br/ brasil/2756216/brasil-contesta-acusacoes-de-protecionismo-feitas-pela-omc>. Acesso em 19 jul. 2012.

NASSER, Rabih Ali. A liberalização do comércio internacional nas normas do GATT-OMC. São Paulo: Ltr, 1999.

REBONO, Maria. Introdução ao Comércio Internacional. In: SEGRE, German. Manual prático de comércio exte- rior. São Paulo: Atlas, 2006.

RODRIGUES, Azelma. Carro sem conteúdo nacional pode pagar até 55\% de IPI. Jornal Valor Econômico. Disponível em: <http://www.valor.com.br/empresas/1008502/carro-sem-conteudo-nacional-pode-pagar-ate-55-de-ipi>. Acesso em: 5 jun. 2012.

SEITENFUS, Ricardo. Manual das Organizações Internacionais. 2. ed. Porto Alegre: Livraria do Advogado, 2000.

TOMAZETTE, Marlon. Comércio internacional \& medidas antidumping. Curitiba: Juruá, 2008. 
Para publicar na Revista de Direito Internacional, acesse o endereço eletrônico www.rdi.uniceub.br ou www.brazilianjournal.org.

Observe as normas de publicação, para facilitar e agilizar o trabalho de edição. 